\title{
What is children's agency? A review of conceptualisations used in early childhood education research
}

Jan Varpanen

\section{Introduction}

Chidren's agency (CA) is presently the focus of widespread interest in research on early childhood education (ECE). Numerous academic publications have focused on CA over the last couple of decades, and the concept is seen as vital in studying childhood (Esser, Baader, Betz \& Hungerland, 2016). In the field of education more generally, several reviews of agency have already been published (Charteris \& Smardon, 2018; Eteläpelto, Vähäsantanen, Hökkä \& Paloniemi, 2013; Fu \& Clarke, 2017; Matusov, von Duyke \& Kayumova, 2015; Pantic, 2017). ${ }^{1}$ These reviews are complemented by theoretical work pointing towards various, sometimes mutually contradicting ways of understanding agency that are anchored in rich theoretical traditions (see Edwards, 2005; Esser, Baader, Betz \& Hungerland, 2016; Oswell, 2013; Rainio \& Hilppö, 2017). These general theoretical perspectives work as a background for conceptualising CA in ECE research, where the theoretical richness inherent in the concept of agency has recently begun to be perceived as a strength to be developed rather than a problem to be solved (Rainio \& Hilppö, 2017; see also Rajala, Kumpulainen, Rainio, Hilppö \& Lipponen, 2016; cf. Jadue-Roa \& Whitebread, 2012).

Developing the theoretical richness in CA is complicated by the fact that a similar diversity of meanings is to be found regarding the notion of theory in education. For example, Thomas (2007) draws on several sources to ascertain a dozen different meanings for "theory" and concludes that no shared understanding emerges, even in meta-level inquiries that aim to clarify the term. Similarly, Biesta, Allan and Edwards (2014), describe their edited collection of papers on the

\footnotetext{
${ }^{1}$ The paper by Pantic cited here is not a review. However, her discussion on pages 220-221 is a summary of an earlier review (Pantic, 2015), which was not available to this author. Therefore, I use her summary in the 2017 paper for my discussions of her work.
} 
relationship between theory and education as providing "a range of different starting points for further exploration and discussion" (p. 7), a strikingly modest goal for a collection of twelve papers on a single topic. Thus, in addition to the various theoretical perspectives inherent in the concept of CA, a further layer of complexity exists in terms of the purpose(s) of having a theoretical perspective to $C A$ in the first place. This suggests that, in order to make the most of the theoretical richness inherent in the concept of agency, analytic understanding is needed of the different meanings of theory reflected by conceptualisations of CA.

Some of the assumptions underlying my investigation of these issues should be clarified immediately. In this study, I understand meanings of concepts to be constructed in the social practices where they are used. Furthermore, in the most general sense, theory is a web or constellation of concepts (Mälkki, 2010). Thus, both CA and theory are to be understood in terms of their uses in practice. When research inquiry is seen as one such practice, the conceptualisation of CA and theory become intertwined. This is because one key function for theory in education research is conceptualising the phenomenon being studied (Biesta et al., 2014). Theory acts as a larger system of meaning a researcher uses to conceptualise CA. In addition to setting up the inquiry by helping to conceptualise the phenomenon being studied, theory is also the result of an inquiry (Biesta et al., 2014). Thus, an understanding of theory is reflected in the aims set for the study.

Based on these considerations, my task in this paper is two-fold. First, I aim to create a typology, or a "conceptual map" (Matusov et al. 2015, p. 425), of the theoretical traditions used to conceptualise CA in ECE research. Earlier works have discussed CA on a conceptual level (Esser et al., 2016; Oswell, 2013; Rainio \& Hilppö, 2017) and reviewed agency in general (Charteris \& Smardon, 2018; Eteläpelto, Vähäsantanen, Hökkä \& Paloniemi, 2013; Fu \& Clarke, 2017; Matusov, von Duyke \& Kayumova, 2015). However, no review of the conceptualisations used in ECE research has so far been published, although the age of the children participating in ECE offers a unique perspective on agency as an educational aim, which might lead to different theoretical approaches from what was revealed in the earlier reviews. My aim here is similar to that of Eteläpelto et al. (2013) - to identify larger frameworks used to conceptualise CA.

The second aim of my paper is to analyse how the conceptualisations of CA used in ECE research connect with different understandings of theory in terms of the aims of the inquiry. Analyses from this perspective have generally been lacking in earlier work, which has focused more on identifying 
the different theoretical perspectives that can be used to conceptualise CA as well as the question of how agency should be conceptualised (Esser et al., 2016; Oswell, 2013; Rainio \& Hilppö, 2017). Taken as a whole, the two dimensions of my analysis work towards painting a more detailed picture of the multiplicity of meanings inherent in conceptualisations of CA.

My paper is structured as follows. Before presenting the results of my analysis, I offer a few general notes on the concept of agency (Section 2) and describe the methods used in searching for, choosing, and analysing the publications that comprise my review (Section 3). In Section 4, I move on to the results of my analysis. I first describe the three major theoretical resources used in ECE research (4.1-4.3). I then discuss in more detail the roles the prominent resources have played in research in Section 5, and, in section 6, examine how the conceptualisations used in ECE relate to the earlier reviews conducted in other contexts. I conclude my paper in Section 7 by drawing my arguments together and offering some ideas for future directions.

\section{Introducing agency}

In order to focus on the primary aims of my paper, I will not use the little space I have to delve into the historical background of CA, which is sufficiently covered elsewhere (see Baader, 2016; Oswell, 2013). However, a few general notes are necessary to understand the complexities of agency. First, an encyclopaedia definition for agency is the capacity to act intentionally (Schlosser, 2015). While it is clear that the discussion and problems surrounding agency have taken the concept in a multitude of directions well beyond the bounds of such a simple definition, it is perhaps worth bearing in mind these humble origins amidst the present diversity.

In fact, it could be argued that the notion of intentionality is the origin for much of the tensions inherent in theoretical discussions of agency. On the one hand, intentionality is personal and subjective in that it is connected to the desires and beliefs of the agent (Schlosser, 2015) - to a sense of purpose (Pantic, 2015). On the other hand, the very same connection to desires and beliefs makes intentionality representational and, as such, dependent on socially constructed systems of meaning (Schlosser, 2015). Thus, intentionality introduces a tension between the social and the individual into the very heart of agency. This fundamental tension is manifested in the part agency plays in sociology's evergreen dialectic of structure and agency (Archer 2000; Oswell, 2013). The structure-agency framework is sometimes placed as the focus of analysis in ECE 
research (e.g. Goulart \& Roth, 2010; Varelas, Tucker-Raymond \& Richards, 2015), but more often this debate remains in the background.

The tension between the individual and social can also be seen in an important debate that concerns the ontological status of agency. On the one hand, agency can be seen as the capacity of an individual, something existing in the individual, so to speak. On the other hand, agency can be seen as emerging in social interactions, as located in the relations between different individuals. (e.g. Sugarman \& Sokol, 2012). The distinction can also be formulated as either a person having agency, or their actions having agency. This debate has variously been called the externalist vs internalist account debate (e.g. Sugarman \& Sokol, 2012) or individual vs social aspect debate (e.g. Muhonen, 2016; Rissanen, 2017). Various scholars (Edwards, 2005; Eteläpelto et al., 2013; Muhonen, 2016; Rissanen, 2017; Pantic, 2017) have argued for acknowledging both the social, relational aspects of agency and the individual, subjective aspects, aiming to turn the debate into a question of how the individual and social aspects of agency interact.

The fundamental tension between the individual and social aspects is a necessary background for understanding the different conceptualisations of agency. It already offers a glimpse of the various tensions and multiplicities inherent in the concept, which will be examined in more detail in Section 4.

\section{Concerning method}

\subsection{Acquisition of data}

The concept of ECE, which is crucial in bounding my analysis, has various possible definitions. For this review, I decided on the broadest and most universally applicable definition covering children from zero to eight years of age (see e.g. Yelland \& Kilderry, 2005; cf. Adair, 2014). Furthermore, articles were included in situations where it was difficult to determine whether they meet the criteria or not, for example, when the ages of the children participating in the study were not explicitly stated.

The terms used for the database search were "early childhood", "childcare", "child care", "daycare", "day care", "preschool", "school”, and "pedagogy". Each term was combined with "children's agency". This is not to say that closely related concepts, such as "autonomy", "actant", or "children's voice", and their relationship with agency is a research interest without merit, but for reasons of space, the scope of this review is limited to the concept of agency. To narrow the 
focus to the field of early childhood education, major education databases were used for the searches, namely ERIC (ProQuest), Education database (ProQuest), and Education Research Complete (Ebsco). The database searches were complemented with suggestions from colleagues and "snowball" sampling - that is, checking the references in the already retrieved articles to find more relevant material. The search terms were required to appear in the abstract of the paper. ${ }^{2} \mathrm{~A}$ further criterion was placed in terms of time. As the purpose of my analysis is not to trace the historical roots of CA, only publications from 1998 onwards were included in the analysis. This cutoff was chosen because notable works on agency in other fields were published around that time (e.g. Archer 2000; Emirbayer \& Mische 1998; Holland, Lachicotte, Skinner \& Cain 1998).

To further narrow the search, an initial screening of potentially relevant articles was made based on the abstracts of the articles. The central criteria used in this initial screening process were that a theoretical framework for the concept of agency was named or a discussion of agency took up considerable space in the abstract. Furthermore, when the full texts of the selected papers were given an initial reading, several papers were discarded because the concept of agency was not presented in sufficient detail to enable the intended analysis. The final data set for the study consisted of 35 papers, all of which were empirical studies.

\subsection{Process of analysis and the analytic concept of "theoretical resource"}

To meet the aims of the study, the analytical concept of "theoretical resource" was developed and put to work over the course of the two rounds of analysis. A theoretical resource is a combination of two elements: (1) a theoretical framework used to define agency and (2) its "imagined" uses in research. The two elements of the concept correspond to the two stages of analysis. In what follows, I will explicate the meaning of this by describing in detail the analytical steps taken (see Table 1).

\footnotetext{
${ }^{2}$ A wider search considering all articles mentioning agency would undoubtedly be an interesting endeavour, but such a project is obviously beyond the scope of any individual article.
} 
Table 1. The two rounds of analysis

\begin{tabular}{|l|l|l|}
\hline $\begin{array}{l}\text { Stage and object of } \\
\text { analysis }\end{array}$ & Analytical question(s) & Purpose \\
\hline $\begin{array}{l}\text { 1. The definition of } \\
\text { CA }\end{array}$ & $\begin{array}{l}\text { Does the author explicitly state a } \\
\text { theoretical framework or tradition } \\
\text { for his/her definition of CA? Does the } \\
\text { author cite central works of a } \\
\text { particular tradition? }\end{array}$ & $\begin{array}{l}\text { Identifying the frameworks } \\
\text { used to define agency in } \\
\text { ECE research. }\end{array}$ \\
\hline $\begin{array}{l}\text { 2a. Aims of the } \\
\text { inquiry/research } \\
\text { questions }\end{array}$ & $\begin{array}{l}\text { What kind of knowledge about CA is } \\
\text { sought? Does the study aim at } \\
\text { explanation, understanding, or } \\
\text { emancipation? }\end{array}$ & $\begin{array}{l}\text { Identifying epistemological } \\
\text { assumptions connected } \\
\text { with the frameworks. }\end{array}$ \\
\hline $\begin{array}{l}\text { 2b. Aims of the } \\
\text { inquiry/research } \\
\text { questions }\end{array}$ & $\begin{array}{l}\text { Where is agency to be found? What } \\
\text { is the locus of analysis? }\end{array}$ & $\begin{array}{l}\text { Identifying ontological } \\
\text { assumptions about CA } \\
\text { connected with the } \\
\text { frameworks. }\end{array}$ \\
\hline $\begin{array}{l}\text { 2c. The definition } \\
\text { of CA }\end{array}$ & $\begin{array}{l}\text { How are the theoretical resources } \\
\text { positioned with respect to each } \\
\text { other? (Only for papers where } \\
\text { multiple theoretical resources were } \\
\text { used) }\end{array}$ & $\begin{array}{l}\text { Identifying how the } \\
\text { frameworks are perceived } \\
\text { to fit with each other. }\end{array}$ \\
\hline
\end{tabular}

The first element of the "theoretical resource" is commonly expressed with terms such as "theoretical tradition" or "theoretical framework". In other words, it is a larger system of meaning researchers use in framing an individual concept - in this case, CA. In order to identify the conceptual nets used to define agency, two concrete clues were given. In many cases, a tradition was explicitly stated in the paper. For example, "the socio-cultural view of agency adopted here" (Fisher, 2010, p. 413) was taken to mean that the author draws on socio-cultural theory to make the concept of agency intelligible. In cases where no such statement was made, the citing of frequently referenced works in the context of a tradition was considered an indication of drawing on a conceptual net. For example, citing the works of Foucault was considered an indication of drawing on post-structuralist theory.

The second element of the "theoretical resource" consists of an implicit understanding of theoryas-result inherent in the conceptualisation. ${ }^{3}$ This element is inspired by Paananen's (2017) use of

\footnotetext{
${ }^{3}$ Although the first focus of the analysis is identifying the theoretical traditions used in the data, with an analysis of the research aims only coming second, I do not claim that there is any temporal primacy for the theoretical framework over the aims of research. In fact, it is quite likely that in "real-life", a scholar might begin with an idea of the project's aims and only then come to choose a conceptualisation for the phenomenon being investigated. This possibility does not contradict what I claim about the connectedness of these aspects.
} 
the analytic concept of "imaginary". A key feature I have adopted from her work is the way an "imaginary" combines a framework with the imagined means of achieving a future that is in line with the framework. Paananen uses "imaginaries" to connect ideas of a desired society with the role ECE is thought to play in achieving it. I argue that, analogously, in research on CA, the conceptual net used to frame agency connects with a view of what might be achieved with an inquiry using such a conceptualisation. These views are reflected in the aims or research questions set for the inquiry. Usually, the aims of a research endeavour are explicitly stated and argued for when presenting the results of an inquiry. To draw a detailed picture of the possibly subtle differences between the aims connected with each of the theoretical resources, the explicitly stated aims of the research in each of the papers were subjected to a second round of analysis consisting of three distinct sets of questions.

My analytical questions are based on a discussion by Biesta et al. (2014), where they distinguish between different uses of theory in research. Their Habermasian distinction between theory as explanation, understanding, or emancipation underlies the first question posed in this second round of analysis: what kind of knowledge about agency is sought? Is the aim of the study to offer a causal explanation of agency, to develop a deeper understanding of what agency is, or to expose taken-for-granted assumptions? This question aims at distinguishing between different takes on the question "What knowledge (theory) is for?" that is inherent in the various conceptualisations of agency.

Biesta et al. (2014) note that using theory for explanation, understanding, or emancipation happens at the end of research, when moving from the data to the conclusions. However, they point out that theory also has a role to play at the beginning of an inquiry - that is, in "the construction of the object of research" (ibid., p. 6), which is the focus of my second analytic question: What is the locus of analysis in the study; where is agency to be found? This question reflects the ambiguity regarding the ontological status of agency, as discussed in Section 2 . Thus, it aims at highlighting how different conceptualisations connect with different implicit ontological stances regarding agency.

Finally, a third round was conducted only for papers where multiple theoretical resources were used. Here analytical attention was paid to how the authors position the resources in relation to each other. In this way, it was possible to see if the authors who use multiple theoretical resources perceive their roles similarly. 


\section{Concepts of children's agency}

Six theoretical resources were identified in the data (see Table 2). Two theoretical resources stood out in terms of frequency of use: new sociology of childhood, which featured in eighteen papers, and socio-cultural theory, which featured in sixteen papers. Post-structural theory was used more rarely, but it was often used together with either the new sociology of childhood or socio-cultural theory. For this reason, these three were considered the major choices and I limit my detailed analysis to them. For each, I describe the theoretical background and consider how the concept of agency is positioned within it (Sections 4.1-4.3). In Section 5, I add more details to these prominent theoretical resources by presenting the results from stages $2 a, 2 b$, and $2 c$ of $m y$ analysis.

Table 2. The most frequently used theoretical resources in the data.

\begin{tabular}{|c|c|c|}
\hline Theoretical resource & Theoretical background & Papers where it was used \\
\hline $\begin{array}{l}\text { New sociology of } \\
\text { childhood }\end{array}$ & $\begin{array}{l}\text {-Childhood sociology } \\
\text {-James, Jenks \& Prout, } \\
\text { Corsaro, James \& James }\end{array}$ & $\begin{array}{l}\text { Shaik \& Ebrahim, 2015; Huf, 2013; } \\
\text { Rissanen, 2017; Nind et al., 2010; Griffin, } \\
\text { 2016; MacFarlane \& Cartmel, 2008; } \\
\text { Houen et al., 2016; Katsiada, 2018; } \\
\text { Baraldi, 2014; Breatnach et al., 2017; } \\
\text { Kucirkova, 2016; Wyness, 1999; Gavora, } \\
\text { 2016; Sarti et al., 2017; Baker-Sperry, } \\
\text { 2006; Bjerke, 2011; Mathis, 2016; } \\
\text { Bühler-Niederberg \& Schwittek, } 2014\end{array}$ \\
\hline Socio-cultural theory & $\begin{array}{l}\text {-Marxist psychology } \\
\text {-Vygotsky, Leontiev }\end{array}$ & $\begin{array}{l}\text { Hilppö et al., 2017; Kumpulainen et al., } \\
\text { 2014; Kim \& Roth, 2016; Fisher, 2010; } \\
\text { Kane, 2015; Roth \& Maheux, 2010; Huf, } \\
\text { 2013; Goulart \& Roth, 2010; Stetsenko \& } \\
\text { Ho, 2015; Kuby \& Vaughn, 2015; Wood, } \\
\text { 2014; Shaik \& Ebrahim, 2015; Rissanen, } \\
\text { 2017; Sairanen \& Kumpulainen, 2014; } \\
\text { Sarti et al., 2017; Mathis, } 2016\end{array}$ \\
\hline Post-structuralist theory & $\begin{array}{l}\text {-Continental philosophy } \\
\text {-Foucault, Derrida }\end{array}$ & $\begin{array}{l}\text { Shaik \& Ebrahim, 2015; Wood, 2014; } \\
\text { Kuby \& Vaughn, 2015; Norén, 2015; } \\
\text { MacFarlane \& Cartmel, } 2008\end{array}$ \\
\hline Psychology & $\begin{array}{l}\text {-Psychological theories } \\
\text {-Piaget, Bandura }\end{array}$ & $\begin{array}{l}\text { Reunamo, 2007; Jadue-Roa \& } \\
\text { Whitebread, 2012; Gavora, } 2016\end{array}$ \\
\hline Capabilities approach & -Amartya Sen & $\begin{array}{l}\text { Adair, 2014; Colegrove \& Adair, 2014; } \\
\text { Steckermeier, } 2018\end{array}$ \\
\hline American pragmatism & $\begin{array}{l}\text {-American pragmatism } \\
\text {-Dewey, James, Peirce }\end{array}$ & Caiman \& Lundegård, 2014 \\
\hline
\end{tabular}


The three remaining resources were used relatively infrequently: psychological theories featured in three papers (Gavora, 2016; Jadue-Roa \& Whitebread, 2012; Reunamo, 2007), American pragmatism in one paper (Caiman \& Lundegård, 2014) and the capabilities approach based on Amartya Sen's work in three papers (Adair, 2014; Colegrove \& Adair, 2014; Steckermeier, 2018). Since these resources were used only occasionally, they were not included in the second round of analysis. However, each of the three reveals something important about CA in ECE research when compared with the earlier reviews about agency in other contexts. Therefore, I discuss the three minor resources in more detail in Section 6.

\subsection{Sociology of childhood}

The first theoretical resource found in the data relates to the new sociology of childhood. New sociology of childhood is a research paradigm that emerged during the 1990s as a fresh approach to studying children (Oswell, 2013). The central new postulate it brought into studying ECE was that children are active social agents who actively participate in their cultures and communities (Bjerke, 2011). In other words, compared to the traditional developmental psychology approach, it offers a competing, sociology-inspired paradigm to explain children's lives, starting with the socialontological presupposition that children are actively involved in constructing the social reality of which they are a part (Babić, 2017; Nind, Flewitt \& Payler, 2010). This is also reflected in the fact that in the papers where the new sociology of childhood resource was employed, children's rights were often discussed as well (e.g. Wyness, 1999).

The move into positioning children as active social contributors gives this resource its central content: in one way or another, children are positioned as being capable of influencing what happens in their environment. For example, Griffin (2017) sees agency happening in learning environments that enable "exploration, ownership and control of their learning" (pp. 25-26), while Houen, Danby, Farrell, and Thorpe (2016) emphasize listening to children's voices and giving them chances to make decisions. Thus, CA is about bringing one's views into the world of social interaction - asserting one's subjectivity (MacFarlane \& Cartmel, 2008; see Kucirkova, 2016) - and shaping the social world with those views. In the context of learning, this translates into viewing children as being co-constructors of knowledge instead of merely passive recipients of instruction (Katsiada, Roufidou, Wainwright \& Angeli, 2018; see also Baraldi, 2014). 


\subsection{Socio-cultural theory}

The second theoretical resource found in the data relates to so-called socio-cultural theory. Sociocultural theory has its roots in Marxist (developmental) psychology and more specifically in the works of Lev Vygotsky, which place primacy on participation in cultural practices as the motors of learning and development (Kim \& Roth, 2016). Accordingly, a key ingredient in this resource is how the actions of an individual are mediated by cultural tools, such as language (Hilppö, Lipponen, Kumpulainen \& Rainio, 2017; Kumpulainen, Lipponen, Hilppö \& Mikkola, 2014). In other words, socio-cultural theory emphasizes that CA never occurs in a vacuum; rather, possibilities for agency are created and bound by other people, cultural artefacts, and the objects of action (Fisher, 2010). This fundamental insight has resulted in a rich theoretical discussion, during which the concept of CA has expanded in various directions. In fact, two distinct developments can be identified within the SCT approach.

First, in several studies, children's sense of agency has become the focus of interest (Hilppö et al., 2017; Kumpulainen et al. 2014; Sairanen \& Kumpulainen, 2014). This approach has brought children's own experience of their agency to the centre of attention. The central theoretical tool that has been used to approach the problem consists of the six modalities of agency (Hilppö et al., 2017). Hilppö et al. define modalities, based on works by Greimas and Porter, as well as Fontanille, as "the underlying structure of different cultural narratives that constituted the actors ... and their intentions in relation to an object" (2017, p. 159). In other words, the modalities characterize the individual actor's disposition, such as "to know", "to be able", or "to feel" (ibid.). It is important to note that the modalities of agency are a response to criticism levelled at some forms of the sociocultural resource regarding the theorization of the individual aspects of agency. The main argument of the criticism is that the socio-cultural approach fails to take into account the subjectivity of agents (Eteläpelto et al., 2013; Edwards, 2005, p. 174). Thus, the focus on children's sense of agency is a step towards addressing a key issue regarding the socio-cultural framing of agency.

Second, to complement the active nature of agency, recent theoretical contributions (e.g. Goulart \& Roth, 2010; Huf, 2013; Kim \& Roth, 2016; Kirch \& Ma, 2016; Roth \& Maheux, 2015) have aimed at capturing a more passive aspect that acts to complement active agency. This passivity has been conceptualised as "passibility" (Kim \& Roth, 2016; Roth \& Maheux 2010; cf. Kirch \& Ma, 2016; cf. the alternative concept of "competent submissiveness" in Huf 2013) - that is, the individual's 
capacity to be affected by the socio-cultural environment. Thus, it is argued that the individual must first open up to be affected by cultural tools, and only then can the individual become an agent whose actions are mediated by those same tools. Theoretically speaking, this notion is extremely complex. It requires further elaboration before it can be ascertained whether the concept of passibility successfully captures openness and passivity and can thus complement CA as intended (Kirch \& Ma, 2016).

\subsection{Post-structuralist approach}

The third major resource identified in the data is post-structuralist theory. Post-structuralist theory is connected to names such as Althusser, Bourdieu, Derrida, Deleuze, Foucault, and Latour (Williams 1999), although in ECE Foucault's works from the 1970s have been a key point of reference (see Shaik \& Ebrahim, 2015). While post-structuralism is too broad an endeavour to summarize in a single paper, let alone in one sub-section, the recurring question of subjectivity the constitution of subjects - is pivotal in much of the work done in its name. Central to the poststructuralist position on subjectivity is the prefix "post". Based on Williams' (1999; cf. Oswell, 2013) analysis of the history of post-structuralism, this word has two meanings. First, it refers to the post-enlightenment ${ }^{4}$ - that is, to moving beyond the idea of a centred, pre-given human subject as foundational to social constructs such as knowledge (Williams, 1999). Second, it refers to moving beyond the structuralist position of understanding subjectivity as being constituted by structure (language), although it has been more difficult to give a precise description to this move (see Williams, 1999). Thus, it seeks to avoid both the total disappearance of the subject in structuralism and the transcendent rational individual of the enlightenment.

In ECE, post-structural theory is often seen as an extension of the socio-cultural approach (Shaik \& Ebrahim, 2015; Wood, 2014). It is seen to augment the socio-cultural approach by providing an analysis of power relations. It seems that this view is based on understanding post-structuralist theory as a critique of "the assumption that a knowable world exists that contains absolute universal truths" (Kuby \& Vaughn, 2015, p. 437). Rather, any claim to truth is a way of wielding power over those whom the truth is about. Thus, accepted ways of speaking and acting discourses - gain a constitutive power over individuals: it is no longer the agent that acts on the world and whose actions are mediated by cultural tools (as was the case in the socio-cultural

\footnotetext{
${ }^{4}$ Or post-modern, but this term is loaded with additional implications and is best avoided when talking about poststructuralism (Williams, 1999, p. 1).
} 
approach); it is rather the cultural tools that set up actions for the agents to realize in their practice (Shaik \& Ebrahim, 2015). In a way, the cultural tools - that is, discourses - act through the actors that are subject to them. This leads to the emergence of a new dialectic of agency that nevertheless repeats earlier oppositions between control and freedom: children are subjects of discourses and they have to accept the conditions of the discourses as given, yet, at the same time, the existence of the discourse is a constant struggle for power - for the right to define truth - which opens up possibilities for resistance and alternative action. As Rainio (2010) notes, agency becomes a question of who has the right to define the discourse at hand.

\section{How the theoretical resources are used}

As described in Section 3.2 (see Table 1), stages $2 a, 2 b$, and $2 c$ of the analysis sought to clarify the ways these theoretical resources connect with different understandings of theory. This was done through three analytic foci derived from Biesta et al.'s (2014) discussion of the various uses of theory in research. In this section, I describe the results of my analysis one stage at a time.

First, in stage 2a, I focused on the distinctions between theory as explanation, understanding, or emancipation (Biesta et al., 2014). Two results from this perspective stood out in my analysis. First, there seems to be a shared focus on the dimensions of understanding and emancipation across the literature reviewed. The shared interest took a form that was present in most of the papers: it was argued that the aim of the inquiry was to develop a better understanding of the possibilities of agency. This was then combined either explicitly or implicitly with the idea of using the new understanding to promote $\mathrm{CA}$ in educational practice. This combination of emancipation through understanding could be an example of what Biesta et al. $(2014$, p. 6) call the "redescription" of educational processes. Thus, it connects with the theme of reconceptualising childhood, which has been identified as a key feature of research on agency (Esser et al., 2016).

Beyond this shared focus, there is also a difference in emphasis to be found between sociocultural theory on the one hand and the new sociology of childhood and post-structural theory on the other. Socio-cultural theory is used more to create a better understanding of agency, while the new sociology of childhood and post-structural theory are more often connected to emancipatory aims. As stated, the difference is subtle and cannot be considered categorical in the sense that it would be impossible to use socio-cultural theory in an emancipatory way (see e.g. Hilppö et al., 2017). However, as will become clear below in the discussion regarding the third stage of analysis, 
there is reason to argue that the difference in emphasis is not mere contingency, but a result of how these theoretical resources are "imagined" to work (Paananen, 2017).

Second, in stage 2b, I ascertained whether the theoretical resources construct their object of research differently (Biesta et al., 2014). Concretely speaking, my goal was to determine what kinds of data were collected to analyse CA. As was the case with the first analytical question above, no categorical differences were established, but once again I identified a noticeable difference in emphasis, although here it was between the new sociology of childhood on the one side and the socio-cultural and post-structural theories on the other. In papers where the new sociology of childhood was used as a theoretical resource, the aims set for research often required data to be collected "from the children's perspective". This quest to hear the voice of children in a very concrete way is "undoubtedly a central preoccupation" in the new sociology of childhood, as noted by Spyrou (2016, p. 107). In contrast, papers where socio-cultural and post-structural perspectives were used focused more often on classroom interactions.

The distinction between focusing on the children and focusing on interactions shows that when the new sociology of childhood is used as a theoretical resource, CA is seen as something that exists in the individual (see Section 2). Studies employing socio-cultural and/or post-structural theories in turn posit a more relational ontology for agency (see Edwards, 2005; Esser et al., 2016). This is not to say that investigations using the new sociology of childhood conceptualisation do not account for the social aspects of agency or that a return to the detached rational individual of the enlightenment is proposed (see Oswell, 2013 for an account of the nuances inherent in the new sociology of childhood). More light can be shed on the meaning of this nuanced difference by considering the final stage of analysis.

Stage 2c, the third and final stage, involved ascertaining how the resources are positioned in relation to each other. Here the analysis showed clearly that the authors had a specific role in mind for each of the theoretical resources being used. An illuminating example is the study by Shaik and Ebrahim (2015), which was the only inquiry in the data to employ all three major theoretical resources. With reference to Mayall and Corsaro, they write: "The sociology of childhood casts young children as agents, who are knowledgeable and capable of functioning in effective ways" (ibid., p. 2). Later, they state "The sociocultural perspective of agency is complementary to the sociology of childhood. ... In mediated action ... the agent is the person doing the acting, and ... the tools are the mediational means used by the agent to accomplish that 
action" (ibid.). Finally, a reference to the post-structural tradition completes the set:

"Poststructural theories extend the idea of mediated action through a focus on the way which institutional and social structures shape the agency of individuals. These theories highlight the way in which agency is tied to power relations and the use of strategies" (ibid.). The roles Shaik and Ebrahim set for the theoretical resources were identifiable throughout the data wherever more than one theoretical resource was used. The new sociology of childhood is used to position children as agents (see e.g. Huf, 2013). It functions as an initial assumption without which the research conducted would not make sense. Socio-cultural theory, on the other hand, is used to show how agency happens. With the key concept of mediated action, it is seen as a way of elaborating the details of agentive action (Huf, 2013; Kuby \& Vaughn, 2015). Although the analysis of power relations is an important way of using post-structural theory, it is only one way of expressing a more general function of complicating the obvious (Kuby \& Vaughn, 2015; Macfarlane \& Cartmel, 2008).

The way the theoretical resources are positioned in relation to each other also clarifies the results of the previous two stages of analysis. In case of stage $2 a$, the emphasis on theory as understanding in studies where socio-cultural theory was used draws on its role as the theoretical resource that shows how agency happens. The new sociology of childhood, in turn, sets up previously marginalized children as agents. Post-structural theory, by showing the complexities inherent in what is considered obvious, offers new avenues for thought. The latter two are fundamentally emancipatory moves. In the case of stage $2 b$, the individualistic ontology that underlies the new sociology of childhood is likely due to the role "imagined" for this theoretical resource: claiming children as agents is followed up by highlighting the agency in them, so to speak. The other two resources, with their foci on how agency happens, and the complexities hidden in plain sight, need to engage with more relational settings for agency.

\section{Discussion}

In this section, I consider in more detail how the map of theoretical resources I have constructed in the context of ECE relates to earlier conceptual analyses of agency conducted in the field of education in general. The aim of this comparison is primarily to shed light on how the understandings of agency in ECE connect with understandings of agency elsewhere and - more importantly - how they differ. An important part of the comparison is reflecting on the minor 
resources that were not discussed in the previous section: psychological theories, the capabilities approach and American pragmatism. As noted earlier, each of these can offer valuable insights for understanding what is specific to CA in ECE.

The theoretical resources presently used in the field of ECE are certainly not solely the property of ECE. In fact, some of the earlier reviews (e.g. Eteläpelto et al., 2013; Fu \& Clarke, 2017) contain the same theoretical traditions of post-structuralism and socio-cultural theory, with the main divergence being that instead of using an approach inspired by the new sociology of childhood, these reviewers discuss sociology in general as a framework for agency.

In addition to these similarities, there are also theoretical resources that are not actively used in ECE. Eteläpelto et al. (2013), who discuss agency in the context of working life, add a fourth theoretical resource of the life course approach to the three of sociology, post-structural theory, and socio-cultural theory. Understood in the manner they (Eteläpelto et al., 2013) describe - as the gradual construction of a personal identity over time through the commitment to choices made in the cultural context by the individual - it is no surprise that this approach has not been researched in ECE given the short life histories of the children whose agency is being investigated. However, the life course approach connects with the general dimension of temporality, also discussed by Fu and Clarke (2017), which seems to be missing from the main theoretical resources of ECE, despite its prominent role in some theories of agency (e.g. Archer, 2000; Emirbayer \& Mische, 1998; Hitlin \& Elder, 2007).

This is where one of the minor theoretical resources, American pragmatism, might make a difference. In the data for my review, only Caiman and Lundegård (2014) used American pragmatism as a framework for agency. They understand agency as involving the anticipation of a problem, a course of action, and (possibly) fulfilment. This conceptualisation involves time as a structuring element of agency. Given the lack of attention given to temporality in ECE research on CA and the fact that Archer (2000) and Emirbayer and Mische (1998) - who draw on pragmatism in their work on agency - are often cited in ECE research on agency (e.g. Varelas, Tucker-Raymond \& Richards, 2015; Kucirkova, 2016), the pragmatist tradition merits more attention as a theoretical resource.

A second theoretical resource that is rarely used in ECE research consists of psychological theories of agency. It is surprising to find that the data set for this study does not reflect the rich theoretical 
and empirical history the concept of agency has in the field of psychology (see Sugarman \& Sokol, 2012 for a review). It is unclear why more attention is not given to psychological theories of agency in ECE research. The lack of psychological conceptualisations in my data could simply be a consequence of the methodological choices of using education databases and focusing on the concept of agency, both of which might work to exclude research drawing on psychological theories. However, another possibility seems more likely. CA is often seen as a way of focusing on what the children are instead of what they are becoming. This point of view is evident especially in the new sociology of childhood resource, and it contrasts with the general perspective of developmental psychology, which traditionally focuses on the processes of children becoming adults. Thus, it is quite possible that the popularity of the new sociology of childhood theoretical resource contributes to the relative rarity of psychological theories in research on CA.

In contrast with the previous two resources, the capabilities approach based on Amartya Sen's work (Adair, 2014; Colegrove \& Adair, 2014; Steckermeier, 2018) is a theoretical resource that is not present in the earlier reviews. The key idea of the capabilities approach is the normative claim that the well-being of individuals should be assessed based on what they are able to do - that is, the real capabilities they possess (Steckermeier, 2018). In the context of early childhood education, this has been used to conceptualise agency as "being able to influence and make decisions about what and how something is learned in order to expand capabilities" (Adair, 2014, p. 219). It is interesting to note that although the earlier reviews do not explicitly discuss the capabilities approach, it can be seen to cover the three aspects of competence, autonomy, and reflexivity, which Pantic (2017) identifies as key aspects of agency. Pantic's fourth key aspect, sense of purpose, comes very close to the notion of sense of agency, as discussed in the context of socio-cultural theory (see Section 4.2). Despite these connections with Pantic's conceptualisation, the capabilities approach appears to be a theoretical resource that is unique to ECE.

In addition to the works discussed above, a few of the earlier reviews have categorized understandings of agency from entirely different perspectives. Charteris and Smardon (2018) discuss four types of agency: sovereign agency, relational agency, ecological agency, and new material agency. Although Charteris and Smardon do not explicitly define the theoretical backgrounds of these four understandings of agency, the first three connect quite straightforwardly to the main parts of my map. On the other hand, based on this review, "new material" agency (ibid., pp. 60-62) has not been investigated in ECE relative to children. However, 
given the recent interest in this perspective (see Oswell, 2013), it is quite possible that this interpretation of CA has been investigated using other, closely related concepts that fall outside the scope of the present inquiry. In addition, the post-structuralist literature certainly offers tools for future inquiries into new material agency. It can be concluded that despite the differing typology, the existing theoretical resources also provide the tools for studying the issues raised by Charteris and Smardon in ECE.

Finally, Matusov et al. (2016) distinguish between four senses of normative agency: instrumental, effortful, dynamically emergent, and authorial. Their categories of instrumental and effortful agency (ibid., pp. 426-432) could be understood through the socio-cultural approach as, respectively, the appropriation of cultural tools and the disposition to use them, while their notion of dynamically emergent agency (ibid., pp. 432-434) has similarities with the post-structural conceptualisation. However, the notion of authorial agency (ibid., p. 435), with its focus on transcending - moving beyond - the given through existing cultural materials, is not explicitly captured by the theoretical resources used in ECE. Since Matusov et al. trace their concept of authorial agency from socio-cultural theory, it is quite possible that further development of the socio-cultural conceptualisation of agency in ECE could benefit from considering the notion of authorial agency.

\section{Conclusions}

To summarize, I have explored how CA is conceptualised in ECE research. I have identified theoretical resources that have been used extensively in ECE and elsewhere (new sociology of childhood, socio-cultural theory, post-structural theory), theoretical resources that are used elsewhere but are rare in ECE (psychological theories, American pragmatism), and a theoretical resource that has been used in ECE but not elsewhere (the capabilities approach). Furthermore, I have indicated how the three major choices - new sociology of childhood, socio-cultural theory and post-structural theory - are connected with implicit understandings of theory in terms of its role in research. As a whole, my results contribute to a more nuanced understanding of the conceptualisations of CA in ECE research.

I was naturally forced to leave out several interesting perspectives related to, for example, institutional factors influencing CA or pedagogical approaches that highlight CA, such as the Reggio Emilia approach (see Edwards, Gandini \& Forman, 1996). By contributing to a more thorough 
understanding of the concept of CA, I hope to enable future research to better address such issues relevant to the praxis of ECE.

My review also shows that despite the extensive interest in the phenomenon of $C A$, the range of research aims seems relatively limited. Building on the discussion of the theoretical resources, important questions remain uninvestigated. A few notable exceptions (Caiman \& Lundegård, 2014; Jadue-Roa \& Whitebread, 2012; Rainio \& Hilppö, 2017) notwithstanding, there do not seem to be many investigations into how CA develops over time. Furthermore, the internal temporal structure of agency as conceptualised by Emirbayer and Mische (1998) has not received any explicit attention. Thus, the dimension of time seems in general to be underrepresented in the research so far.

Additionally, based on the data set of this study, it seems that the importance of CA is taken for granted: few have asked why agency is important or why it has suddenly become so important in ECE. This reflects Lancy's (2012) criticism of what he sees as the "agency movement": most of the research is focused on demonstrating how CA is possible, but there are hardly any studies that seek the limits of that agency or offer critical accounts of why the concept of agency is so prominent in many ECE curricula these days. A related question that has also received scant attention is what purpose CA actually serves. In a sense, agency is an empty concept that tells us nothing of the action it enables, except that the action should be influential. Therefore, it is necessary to ask what types of aims of education CA relates to and how these have come to be seen as important. This might also open avenues for investigating the normative question of distinguishing between worthwhile and non-worthwhile forms of CA (Renshaw, 2016). The capabilities approach, with its focus on the relationship between agency and well-being, might be a useful theoretical resource in addressing these issues.

To conclude, the initial steps I have taken towards understanding the different uses of conceptualisations of CA can help future research in making the most of a recent shift towards embracing the complexities inherent in $\mathrm{CA}$ as a productive feature. The productivity of the inherent complexity of agency is epitomized by the argument of Rainio and Hilppö (2017; see also Rainio, 2010), who call for a dialectical conceptualisation of agency. As the analysis in Section 5 shows, the different conceptualisations are not used dialectically in the papers included in this review. Rather, they are described as complementing each other without contradictions (see e.g. Shaik \& Ebrahim, 2015). This way of using the theoretical resources introduces the risk discussed 
by Thomas (2007), who argues that theory is inherently constraining in that it defines beforehand what can be discovered in research. This risk can be seen, for example, in the way the theoretical resources "imagine" their object of research as either individual or relational. The constraint of theory can be alleviated by using several theoretical resources, which allows for a broader spectrum of "imagined" possibilities. However, if several theoretical resources are used uncritically and without paying sufficient attention to their possible incompatibilities, one runs the risk of returning to the simplified view one was trying to avoid in the first place (see Mälkki, 2010). Consequently, and in line with Rainio and Hilppö (2017), I suggest that researchers wishing to use several theoretical resources should use them in a way that highlights rather than hides the contradictory aspects, as this approach would be more productive than one trying to present them as complementary. In enabling this, analyses of the kind presented here can prove to be valuable. 


\section{References:}

Adair, J. (2014). Agency and Expanding Capabilities in Early Grade Classrooms: What It Could Mean for Young Children. Harvard Educational Review, 84(2), 217-242.

Archer, M. (2000). Being Human: The Problem of Agency. Cambridge: Cambridge university press.

Baader, M. (2016). Tracing and contextualizing childhood agency from historical and systematic perspectives. In Esser, F., Baader, M., Betz, T. \& Hungerland, B. (eds.) (2016). Reconceptualising Agency and Childhood. New Perspectives in Childhood Studies. London/New York: Routledge, 135-149.

Babić, N. (2017). Continuity and Discontinuity in Education: Example of Transition from Preschool to School. Early Child Development and Care, 187(10), 1596-1609. DOI: $10.1080 / 03004430.2017 .1301935$

Bailey, D. (2018). Getting on their level: preschool teachers embodying the ideal preschooler. Childhood, 25(2), 253-266.

Baker-Sperry, L. (2006). Gendered agency: Power in the elementary classroom. Women and language, 29(2), 38-46.

Baraldi, C. (2014). Promoting Migrant Children's Epistemic Status and Authority in Early School Life. International Journal of Early Childhood, 47, 5-25. DOI 10.1007/s13158-014-0116-7

Biesta, G., Allan, J. \& Edwards, R. (2014). Making a Difference in Theory. The Theory Question in Education and the Education Question in Theory. London/New York: Routledge.

Bjerke, H. (2011). "It's the way they do it": Expressions of Agency in Child-Adult relations in Home and at School. Children \& Society, 25, 93-103.

Breathnach, H., Danby, S. \& O'Gorman, L. (2017). “Are You Working or Playing?" Investigating Young Children's Perspectives of Classroom Activities. International Journal of Early Years Education, 25(4). 439-454, DOI: 10.1080/09669760.2017.1316241 
Bühler-Niederberger, D. \& Schwittek, J. (2014). Young children in Kyrgyzstan: Agency in tight hierarchical structures. Childhood, 21(4), 502-516.

Caiman, C. \& Lundegård, I. (2014). Pre-school CA in Learning for Sustainable Development. Environmental Education Research, 20(4), 437-459. http://dx.doi.org/10.1080/13504622.2013.812722

Charteris, J. \& Smardon, D. (2018). A Typology of Agency in New Generation Learning Environments: Emerging Relational, Ecological and New Material Considerations. Pedagogy, Culture \& Society, 26(1), 51-68, DOI: 10.1080/14681366.2017.1345975

Colegrove, K. \& Adair, J. (2014). Countering Deficit Thinking: Agency, Capabilities and the Early Learning Experiences of Children of Latino/a Immigrants. Contemporary Issues in Early Childhood, 15(2), 122-135. http://dx.doi.org/10.2304/ciec.2014.15.2.122

Edwards, A. (2005). Relational agency: Learning to be a resourceful practitioner. International journal of educational research 43(3), 168-182.

Edwards, C., Gandini, L. \& Forman, G. (eds.) (1996). The hundred languages of children: the Reggio Emilia approach to early childhood education. Norwood: Ablex publishing corporation.

Emirbayer, M. \& Mische, A. (1998). What Is Agency? The American Journal of Sociology, 103(4), 962-1023.

Esser, F., Baader, M., Betz, T. \& Hungerland, B. (eds.) (2016). Reconceptualising Agency and Childhood. New Perspectives in Childhood Studies. London/New York: Routledge.

Eteläpelto, A., Vähäsantanen, K., Hökkä, P. \& Paloniemi, S. (2013). What Is Agency? Conceptualising Professional Agency at Work. Educational Research Review, 10, 4565. http://dx.doi.org/10.1016/j.edurev.2013.05.001

Fisher, R. (2010). Young Writers' Construction of Agency. Journal of Early Childhood Literacy, 10(4), 410-429. DOI: 10.1177/1468798410382407 
Fu, G. \& Clarke, A. (2017). Teacher Agency in the Canadian Context: Linking the How and the What. Journal of Education for Teaching, 43(5), 581-593, DOI:

$10.1080 / 02607476.2017 .1355046$

Gavora, P. (2016). Preschool children in book-reading situations with parents: the perspective of personal agency theory. Studia paedagogica, 21(4), 100-116.

Goulard, M. \& Roth, W.-M. (2010). Engaging Young Children in Collective Curriculum Design. Cultural Studies of Science Education, 5, 533-562. DOI 10.1007/s11422-009-9196-3

Griffin, S. (2017). The Fluid Infusion of Musical Culture: Embodied Experiences in a Grade One Classroom. Pedagogies: An International Journal, 12(1), 21-40. DOI: $10.1080 / 1554480 X .2017 .1283993$

Hilppö, J., Lipponen, L., Kumpulainen, K. \& Rainio, A. (2017). Children's Sense of Agency in Preschool: A Sociocultural Investigation. International Journal of Early Years Education, 24(2), 157-171. DOI: 10.1080/09669760.2016.1167676

Hitlin, S. \& Elder, G. (2007). Time, Self, and the Curiously Abstract Concept of Agency. Sociological Theory, 25(2), 170-191.

Holland, D., Lachicotte, W., Skinner, D. \& Cain, C. (1998). Identity and Agency in Cultural Worlds. Cambridge: Harvard university press.

Houen, S., Danby, S., Farrell, A. \& Thorpe, K. (2016). Creating Spaces for CA: "I wonder..." Formulations in Teacher-Child Interactions. International Journal of Early Childhood, 48, 3, 259-276. DOI 10.1007/s13158-016-0170-4

Huf, C. (2013). CA During Transition to Formal Schooling. Ethnography and Education, 8, 1, 61-76. http://dx.doi.org/10.1080/17457823.2013.766434

Jadue-Roa, D. \& Whitebread, D. (2012). Young Children's Experiences Through Transition Between Kindergarten and First Grade in Chile and Its Relation with Their Developing Learning Agency. Educational and Child Psychology, 29(1), 32-46. 
Kalliala, M. (2014). Toddlers as Both More and Less Competent Social Actors in Finnish Day Care Centres. Early Years, 34(1), 4-17. DOI: 10.1080/09575146.2013.854320

Kane, J. (2015). The Structure-Agency Dialectic in Contested Science Spaces: "Do Earthworms Eat Apples?" Journal of Research in Science Teaching, 52(4), 461-473. DOI10.1002/tea.21206

Katsiada, E., Roufidou, I., Wainwright, J. \& Angeli, V. (2018). Young CA: Exploring Children's Interactions with Practitioners and Ancillary Staff Members in Greek Early Childhood Education and Care Settings. Early Child Development and Care, 188(7), 937-950. DOI: $10.1080 / 03004430.2018 .1446429$

Kim, M. \& Roth, W.-M. (2016). Beyond Agency: Sources of Knowing and Learning in Children's Science- and Technology-Related Problem Solving. Cultural Studies of Science Education, 11(4), 1081-1101. DOI 10.1007/s11422-015-9683-7

Kirch, S. \& Ma, J. (2016). The Relationship Between Passibility, Agency and Social Interaction and Its Relevance for Research and Pedagogy. Cultural Studies of Science Education, 11(4), 1103-1113. DOI: $10.1007 / \mathrm{s} 11422-015-9726-0$

Kuby, C. \& Vaughn, M. (2015). Young Children's Identities Becoming: Exploring Agency in the Creation of Multimodal Literacies. Journal of Early Childhood literacy, 15(4), 433-472. DOI: $10.1177 / 1468798414566703$

Kucirkova, N. (2016). Personalisation: A Theoretical Possibility to Reinvigorate Children's Interest in Storybook Reading and Facilitate Greater Book Diversity. Contemporary Issues in Early Childhood, 17(3), 304-316. DOI: 10.1177/1463949116660950

Kumpulainen, K., Lipponen, L., Hilppö, J. \& Mikkola, A. (2014). Building on the Positive in Children's Lives: A Co-Participatory Study on the Social Construction of Children's Sense of Agency. Early Child Development and Care, 184(2), 211-229. DOI: 10.1080/03004430.2013.778253

Lancy, D. (2012). Unmasking CA. AnthropoChildren, 2012, 2. http://popups.ulg.ac.be/AnthropoChildren/document.php?id=1253

MacFarlane, K. \& Cartmel, J. (2008). Playgrounds of Learning: Valuing Competence and Agency in Birth to Three-Year-Olds. Australian Journal of Early Childhood, 33(2), 41-47. 
Matusov, E., von Duyke, K., \& Kayumova, S. (2015). Mapping Concepts of Agency in Educational Contexts. Integrative Psychological and Behavioral Science, 50(3), 420-446. DOI $10.1007 / \mathrm{s} 12124-015-9336-0$

Mathis, J. (2016). Literature and the Young Child: Engagement, Enactment and Agency from the Sociocultural Perspective. Journal of research in childhood education, 30(4), 618-629.

Muhonen, S. (2016). Students' Experiences of Collaborative Creation through Songcrafting in Primary School: Supporting Creative Agency in "School Music" Programmes. British Journal of Music Education, 33(3), 263-281. DOI: 10.1017/S0265051716000176

Mälkki, K. (2010). Building on Mezirow's Theory of Transformative Learning: Theorizing the Challenges to Reflection. Journal of Transformative Education, 8(42), 42-62. DOI: $10.1177 / 1541344611403315$

Nind, M., Flewitt, R. \& Payler, J. (2010). The Social Experience of Early Childhood for Children with Learning Disabilities: Inclusion, Competence and Agency. British Journal of Sociology of Education, 31(6), 653-670. DOI: 10.1080/01425692.2010.515113

Norén, E. (2015). Agency and Positioning in a Multilingual Mathematics Classroom. Educational Studies in Mathematics, 89(2), 167-184. DOI 10.1007/s10649-015-9603-5

Oswell, D. (2013). The Agency of Children. From Family to Global Human Rights. Cambridge: Cambridge university press.

Paananen, M. (2017). The imaginaries that survived: Societal roles for early childhood education in an era of intensification. Global studies of childhood, https://doi.org/10.1177/2043610617704934

Pantic, N. (2017). An exploratory study of teacher agency for social justice. Teaching and teacher education, 66(8), 219-230.

Pantic, N. (2015). A model for study of teacher agency for social justice. Teachers and Teaching: Theory and Practice, 21(6), 759-778. 
Rainio, A. \& Hilppö, J. (2017). The Dialectics of Agency in Educational Ethnography. Ethnography and Education, 12(1), 78-94. DOI: 10.1080/17457823.2016.1159971

Rainio, A. (2010). Lionhearts of the Playworld. Helsinki: Helsinki university press.

Rajala, A., Kumpulainen, K., Rainio, A.P., Hilppö, J. \& Lipponen, L. (2016). Dealing with the Contradiction of Agency and Control During Dialogic Teaching. Learning, Culture and Social Interaction, 10, 17-26. http://dx.doi.org/10.1016/i.Icsi.2016.02.005

Renshaw, P. (2016). On the Notion of Worthwhile Agency in Reformist Pedagogies. Learning, Culture and Social Interaction, 30, 60-63. http://dx.doi.org/10.1016/j.Icsi.2016.07.002

Reunamo, J. (2007). Adaptation and Agency in Early Childhood Education. European Early Childhood Education Research Journal, 15(3), 365-377. DOI: 10.1080/13502930701679304

Rissanen, M. (2017). “It's as if..." Preschoolers Encountering Contemporary Photography. International Journal of Education \& the Arts, 18(28), 1-29.

Roth, W.-M. \& Maheux, J.-F. (2015). The Visible and the Invisible: Mathematics as Revelation. Educational Studies in Mathematics, 88(2), 221-238. DOI 10.1007/s10649-014-9582-y

Sairanen, H. \& Kumpulainen, K. (2014). A visual narrative inquiry into children's sense of agency in preschool and first grade. International Journal of Educational Psychology, 3(2), 141-174.

Sarti, A., Dijkstra, C., Nury, E., Seidell, J. \& Dedding, C. (2017). Children \& society, 31 429-440.

Schlosser, M. (2015) "Agency", The Stanford Encyclopedia of Philosophy (Fall 2015 Edition), Edward N. Zalta (ed.), URL = <https://plato.stanford.edu/archives/fall2015/entries/agency/>

Shaik, N., \& Ebrahim, B. (2015). CA in Grade R: A Case for a Child Participation Focus. South African Journal of Education, 35(2), 1-8. DOI: 10.15700/saje.v35n2a1064

Spyrou, S. (2016). Troubling Children's Voices in Research. In Esser, F., Baader, M., Betz, T. \& Hungerland, B. (eds.) (2016). Reconceptualising Agency and Childhood. New Perspectives in Childhood Studies. London/New York: Routledge, 105-118. 
Steckermeier, L. (2018). Better safe than sorry. Does agency moderate the relevance of safety perceptions for the subjective well-being of young children? Child indicators research, $12(1), 29-48$.

Stetsenko, A. \& Ho, P.-C. (2015). The Serious Joy and the Joyful Work of Play: Children Becoming Agentive Actors in Co-Authoring Themselves and Their World through Play. International Journal of Early Childhood, 47(2), 221-234. DOI 10.1007/s13158-015-0141-1

Sugarman, J. \& Sokol, B. (2012). Human Agency and Development: An Introduction and Theoretical Sketch. New Ideas in Psychology, 30, 1-14.

DOI:10.1016/j.newideapsych.2010.03.001

Thomas, G. (2007). Education and Theory: Strangers in Paradigms. Maidenhead: Open University Press.

Varelas, M., Tucker-Raymond, E. \& Richards, K. (2015). A Structure-Agency Perspective on Young Children's Engagement in School Science: Carlos's Performance and Narrative. Journal of Research in Science Teaching 52(4), 516-529. DOI 10.1002/tea.21211

West, D. (2010). Continental philosophy: An introduction. Cambridge: Polity press.

Williams, G. (1999). French Discourse Analysis. The Method of Poststructuralism. London \& New York; Routledge.

Wolters, E. (2013). “Foucault on obscurantism: They made me do it!" Retrieved from http://www.critical-theory.com/foucault-obscurantism-they-it/

Wood, E. (2014). Free Choice and Free Play in Early Childhood Education: Troubling the Resource. International Journal of Early Years Education, 22(1), 4-18. http://dx.doi.org/10.1080/09669760.2013.830562

Wyness, M. (1999). Childhood, agency and educational reform. Childhood, 6(3), 353-368.

Yelland, N. \& Kilderry, A. (2005). Against the Tide. New Ways in Early Childhood Education. In N. Yelland (ed.), Critical Issues in Early Childhood Education (pp. 1-14). Maidenhead: McGrawHill Education. 